\title{
The Interactivity of a Virtual Museum at the Service of the Teaching of Applied Geology
}

\author{
Gómez-Fernández, Fernando ; Fernández Raga, María ${ }^{\mathrm{b}}$; Alaiz, Héctor ${ }^{\mathrm{c}}$; Castañón, \\ Ana María and Palencia, Covadonga ${ }^{b}$ \\ ${ }^{\mathrm{a}}$ School of Mining Engineering, University of León, Spain; ${ }^{\mathrm{b}}$ Department of Applied \\ Chemistry and Physics, University of León, Spain; ${ }^{c}$ Department of Electrical Engineering \\ and Systems and Automation, University of León, Spain.
}

\begin{abstract}
In a framework in which teaching practice is a dynamic process, predisposed to continuous innovation, the Geological Collection of the University of León (CGULe), with 2000 copies of minerals, rocks and fossils, offers an opportunity for teaching innovation, in relationship with subjects of the geological disciplines that are taught in the Degrees of Mining Engineering and Energy Engineering.

At http://laboratorio.wesped.es/, the first phase of development of the Virtual Museum of the CGULe is shown, where information and images of minerals and mineral deposits from León are offered. Likewise, videos of tests of characterization of minerals, made by students as a practice of the subject "Mineralogy and Petrography" (Degree in Mining Engineering), are offered as part of a teaching innovation. This teaching innovation was evaluated in two ways: a) comparing the academic results of students in this practice with equivalent results from previous courses and b) conducting a satisfaction survey. Given the small number of students who participated in this experience, the results of this evaluation are inconclusive. For this reason, teacher innovation will be extended in time and will be extended to other subjects of the above mentioned degrees.
\end{abstract}

Keywords: Teacher innovation; Mineralogy; Ore deposits; virtual museum. 


\section{Introduction}

Museums throughout history have changed in their conception and have gone from presenting a mere collection of knowledge to being one of the best didactic resources at the service of people. Methodologically, virtual museums can be an educational resource in which to present motivational virtual activities that dynamize the teaching-learning process and foster creativity and scientific vocations.

The Geological Collection of the University of León (CGULe), has around 2000 specimens of minerals, rocks and fossils and is located in the facilities of the Superior and Technical School of Mining Engineers of this university. In a framework in which teaching practice is a dynamic process, predisposed to continuous innovation, CGULe offers us a unique opportunity for teaching innovation, especially in relation to the subjects of "Mineralogy and Petrography", "Geology", "Minerals" and "Stratigraphy and Paleontology" taught in the Degrees of Mining Engineering and Energy Engineering.

There are numerous antecedents of creation of virtual museums related to geological disciplines (i.e. Fernández Caliani, 2011; Tambuyser \& Hootelé, 2011; Griem, 2015). In this paper, the results of the initial development phase of the Virtual Museum of the CGULe (http://laboratorio.wesped.es/) are presented. The work carried out is linked to a pilot teaching innovation project at the University of León, which was carried out on a small number of mineral samples from León metallic deposits. This theme was chosen because of its local singularity, since possibly no other museum has the capacity to present an equivalent exhibition.

\section{Metodology}

In the first phase of construction of the CGULe Virtual Museum shown in this article, the platforms Thinglink and Wordpress were used (https://srd.wordpress.org/plugins/thinglink), with a plugin that allows to make images interactive from a website by tagging with Rich Media Tags like YouTube, SoundCloud, Spotify, Amazon and many others. The work was structured in three sections: the musealization of the minerals and deposits from León, the realization of videos of the tests and the evaluation of the teaching innovation related to the construction of the museum. They are described in detail below: 


\subsection{Virtual Musealization of Reserves and Mineral Species}

A map of the deposits of the main minerals of interest has been made. Based on information compiled from specialized magazines, a descriptive file has been made of each of the main mines.

On the other hand, relevant samples of minerals from these deposits belonging to the CGULe have been photographed and a descriptive sheet of each mineral species has been made.

\subsection{Videos of Mineral Characterization Tests}

The students of the subject "Mineralogy and Petrography" of the 3rd year of the Degree in Mining Engineering (course 2016-17), in groups of two and under the supervision of the teacher of the subject, elaborated scripts and made videos on significant physical-chemical properties for the identification and classification of minerals.

\subsection{Evaluation of teacher innovation}

The work described in the previous section was carried out by the students as a practice of the subject "Mineralogy and Petrography", which implied a teaching innovation with respect to previous academic courses, whose effectiveness was evaluated in two ways:

- Comparison of the grades obtained by the students in the practice of "Recognition and classification of minerals" with grades obtained by students in the three previous academic courses.

- Satisfaction survey completed by the students. The sections of this survey that are detailed, together with the results, in section 3.3.

\subsection{Technical Description}

The core of the Mineral Museum website is a Wordpress CMS (Content Management System) (WordPress, n.d.) running in an Apache Web Server. Wordpress is the most popular CMS due to it is easy to use and maintain. This CMS can work with multiple plugins such as DIVI and Thinglink (Thinglink Company, n.d.). DIVI is a visual Wordpress theme editor that allows to develop web content without the necessity to have advanced knowledge in a specific language programming such as HTML or PHP. On the other hand, Thinglink has been used as a basis for linking to the interactive image management platform. Video content has been supported by Youtube, uploading the videos from the students and teachers's institutional accounts. After that the video content can be linked with Wordpress easily to be included in the Mineral Museum. 


\section{Results}

\subsection{Virtual Musealization of Reserves and Mineral Species}

As a result, the site http://laboratorio.wesped.es/ has been created where all the information indicated in section 2.1 is hosted.

Figure 1A shows the museum home page. For each one of the mineral deposits located in it, we find: images of the deposit itself (Fig. 1B), images of minerals from that deposit (Fig. 1C and 1D), descriptive records of each mineral species (Fig. 1E) and a descriptive analysis of the main site (Fig. 1F).

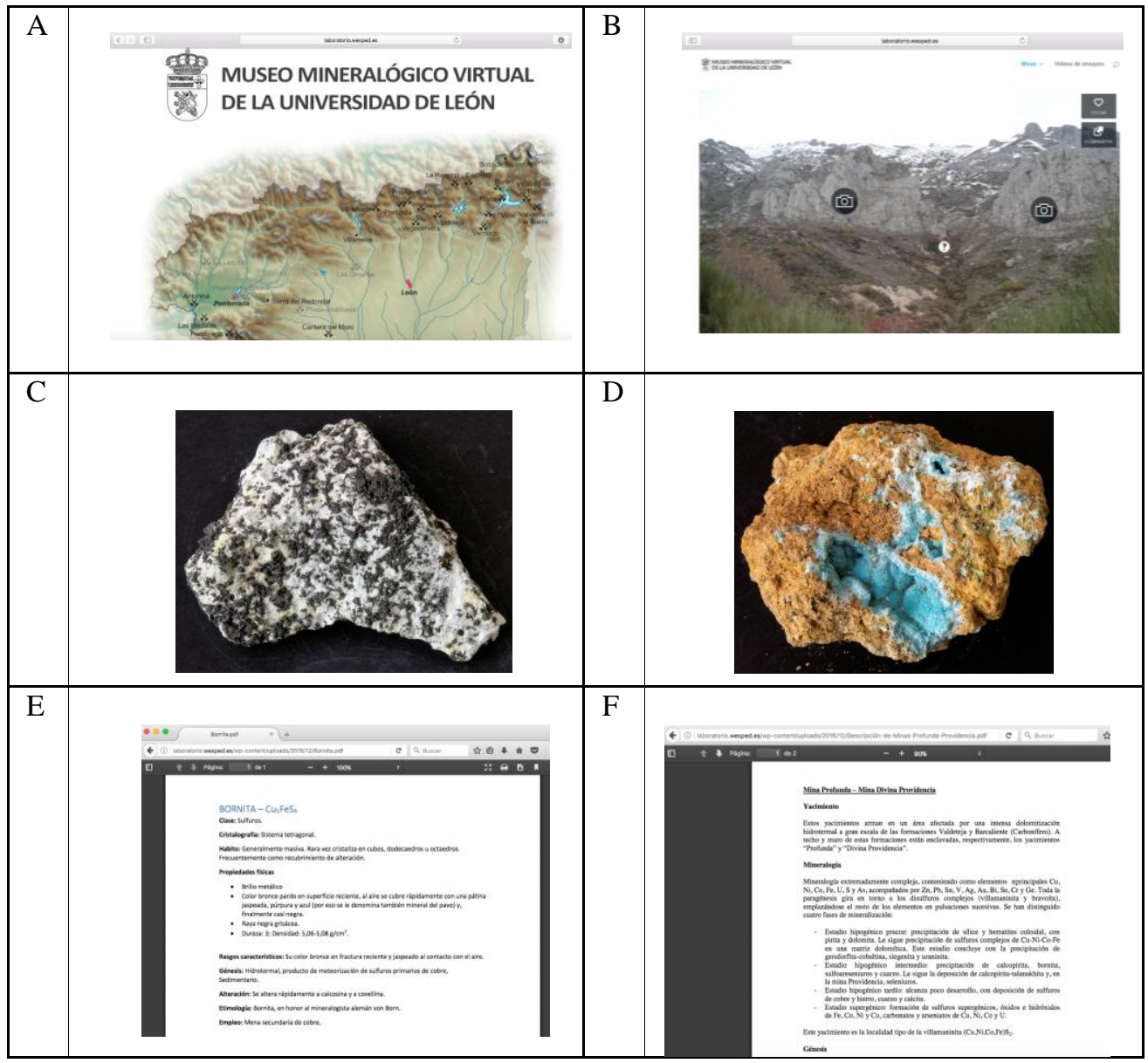

Figure 1. Examples of information available at the virtual museum. 


\subsection{Videos of Mineral Characterization Tests}

A selection of videos on physical and chemical properties of minerals, made by students, is available on the Youtube platform through the link "Videos of Essays" created at http://laboratorio.wesped.es/.

Specifically, videos are exposed on the following properties: color, ray, magnetism, exfoliation, hardness, birefringence, fluorescence and reaction to $\mathrm{HCl}(10 \%)$ in cold.

\subsection{Evaluation of teaching innovation}

Of the 16 students enrolled in the subject "Mineralogy and Petrography" 10 participated in the teaching innovation activity.

Academic qualifications. The average score obtained by the students in the mineral recognition test, after the teaching innovation, was 5.8 points out of 10 . This grade is of the same order of magnitude as those obtained in the previous three academic years (5.5 points out of 10), although slightly superior to it.

Satisfaction survey. To the question: do you think that you needed more explanations prior to the realization of the practices?, $70 \%$ of the students believe that the explanations were sufficient (Fig 2).

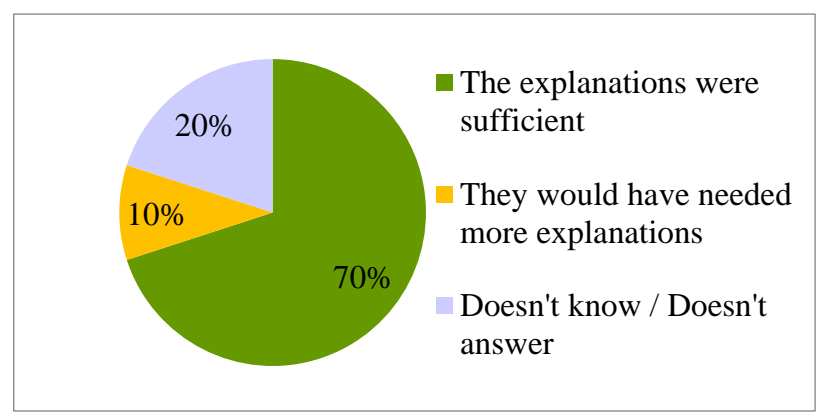

Figure 2. Comments on the training prior to the implementation of the practice.

Other sections of this survey were:

A1. The practice of video recording of the tests of physical properties of minerals has been useful and simple.

A2. The elaboration of the scripts of the videos realized has been useful and simple to me.

A1. The fact that the best videos made by the students would be uploaded to the virtual museum has positively influenced my motivation when doing the practice.

A4. I think I've learned more than if I had done a conventional equivalent practice. 
A5. Is the practical methodology developed adequate for the subject "Mineralogy and Petrography"?

A6. I would like the other practices of the subject to be related to the development of the virtual museum.

A7. Do you think that the participation of the students is interesting for the development of the virtual museum?

The answers obtained in each of these sections are shown graphically in Figure 3.

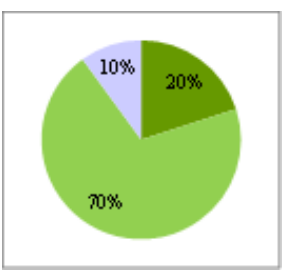

A1

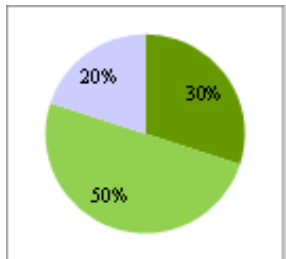

A5

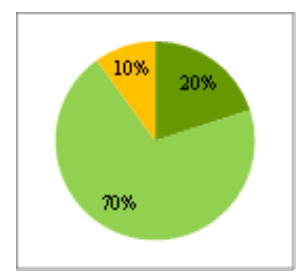

A2

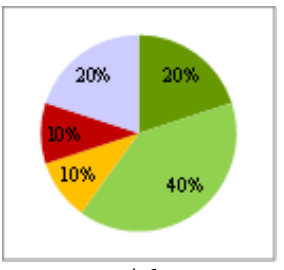

A6

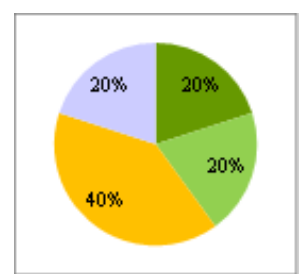

A3

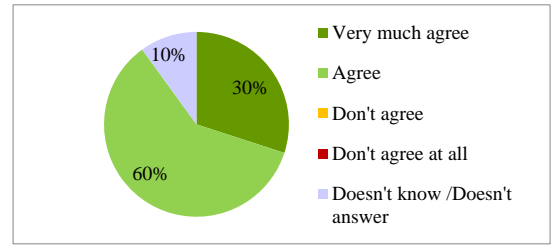

A7 and Legend

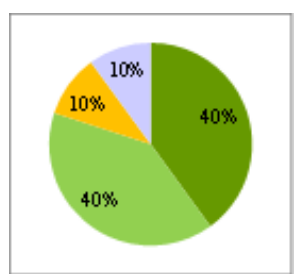

A4

Figure 3. Pie charts showing students' responses to the satisfaction survey.

Students were asked to suggest what was the most and the less interesting aspects to them when realizing this experience and the answers are collected in Figure 4.

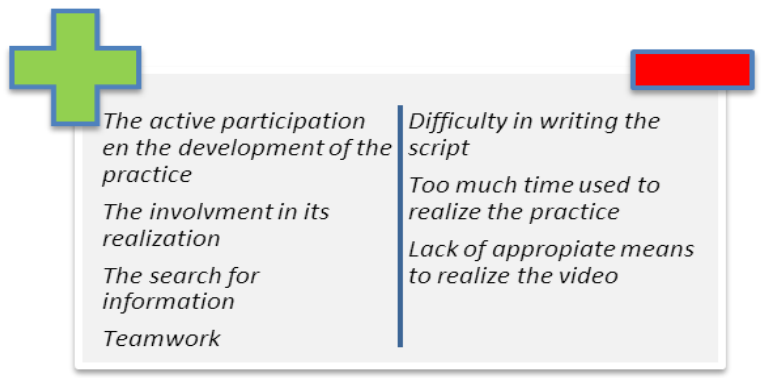

Figure 4. Comments on the practice. 
Some respondents have made suggestions for future practices, that point toward to consider to carry out and expand this kind of experiences, as well as implement technical support when making the videos, to improve their quality.

\section{Discussion}

Virtual museums 2.0 are a very powerful tool for disseminating information, and also facilitate and enhance the interaction between institutions and the public (Capriotti et al., 2016). In this experience, the University of León and the students are linked by the creation of this Museum experience. Also, the creation of the virtual museum is a first achievement, related directly to the teaching innovation in the subjects "Mineralogy and Petrography", of the Degree of Mining Engineering.

The academic results of the practical test of mineral recognition, performed by the students after the teaching innovation, are of the same order of magnitude as the equivalent results of previous academic courses. Although the results of the survey completed by the students show a high satisfaction with the teaching innovation carried out. They also show the desire to extend the experience to other practical contents of the subject, pointing out also show some room for improvement. Given that the number of pupils who have participated in this teaching innovation is very small (10), the interpretation of the results obtained, so far, has a very limited validation. For this reason, teaching innovation will be extended during the next course to the subject of "Geology" (Grades in Mining Engineering and Energy Engineering) and in subsequent courses of the subjects "Mineral Deposits" and "Stratigraphy and Paleontology" (Degree in Mining Engineering).

\section{Conclusions}

One of the main objectives of the project for the creation of the website of the virtual museum, can already be consulted at http://laboratorio.wesped.es/. It is a web page in its initial phase of development, whose growth is projected into the future. The museum currently shows information that corresponds to metallic deposits from León and some minerals from these deposits. The museum also shows videos with information on methodologies of tests for identification and characterization of minerals. These videos were made by students of the subject "Mineralogy and Petrography" (Degree in Mining Engineering) within a framework of teaching innovation while the practices of this subject.

The evaluation of this teaching innovation has been carried out in two ways: a) Comparison of academic results of students with the equivalent results of previous academic courses and b) Conduct and analysis of satisfaction surveys. Only the ten students who had to surpass 
the practices of this subject participated in these surveys. Given the small number of the samples, the results are inconclusive. However, they serve as a first approach to debug future lines of work. Hence during the current and future courses it is intended to extend the sampling to students of other subjects of the Mining Engineering and Energy Engineering degrees in order to obtain a reliable evaluation of teaching innovation projects linked to the development of the museum.

\section{Acknowledgments}

The work was partially funded by the project "Design of practical teaching-learning experiences in relation to the virtual musealization of the Geological Collection of the University of León", in the framework of the Support Plan for Teaching Innovation of the University of León (PAID \& PAGID 2016). Likewise, the authors express their gratitude to D. Luis Armando Conejo Lombas, donor of copies to the Geological Collection of the University of Leon, as well as photographs of deposits to the Virtual Museum, and to the collaborators: Mr. Ángel Díez Bragado, Mr. Jesús García del Canto, Mr. Manuel Urcera Valladares and Mr. Guillermo Salazar Brugos.

\section{References}

Capriotti, P., Carretón, C., \& Castillo, A. (2016). Testing the level of interactivity of institutional websites: From museums 1.0 to museums 2.0. International Journal of Information Management, 36 (1), 97-104.

Divi INC. (n.d.). Retrieved January 20, 2017 https://www.elegantthemes.com/gallery/divi/

Fernández Caliani, J.C. (2011). Museo de Mineralogía de la Universidad de Huelva. Retrieved January 24, 2017, from http://www.uhu.es/museovirtualdemineralogia/

Griem, W. (2015). Museo Virtual de Geología. Retrieved January 24, 2017, from http://www.geovirtual2.cl/geologiageneral/ggcap04a.htm

Tambuyser, P., \& Hootelé, C. (2011). Virtual Museum of the History of Mineralogy. Retrieved January 24, 2017, from http://www.mineralogy.eu/

Thinglink Company (n.d.). Retrieved January 20, 2017, from https://www.thinglink.com/

WordPress (n.d.). Retrieved January 20, 2017, from https://es.wordpress.com/features/ 